\section{Enhancing the image of mathematics by association with simple pleasures from real world contexts}

\author{
Robyn Pierce, University of Ballarat \\ Kaye Stacey, University of Melbourne
}

\begin{abstract}
Those who market people or products choose their images very carefully. They create positive associations in the public's mind by photographing their clients with sporting heroes or national icons. In this paper we present a variety of evidence to show that a major and overlooked reason for teachers' use and choice of real world problems is to take advantage of this 'halo effect' to improve students' attitude towards learning mathematics. Analysis of interviews, reports, and results of a brief survey from teachers of middle secondary school classes indicate that they place a very high priority on positive attitudes and hence both choose and enhance real world problems to promote students' affective engagement through simple pleasures. Pleasant sensory stimuli, generally non-cognitive and peripheral to the situation to be modelled, are used to promote a positive view of mathematics. This is a good strategy for creating enjoyable and memorable lessons, but there is a danger that it may override more substantive learning goals.
\end{abstract}

\section{ZDM-Classification: C23}

\section{Introduction}

\subsection{Why use real world problems?}

Student 1: You can relate things - it's not just a lot of numbers and things on the paper - so when you have the answer it actually makes sense.

Student 2: More interesting, yes, I liked the lemonade one because I used to make lemonade squash when I was little.

These encouraging responses from two students, studying a Year 9 mathematics topic through considering real world problems, encapsulate the values of teaching through real world context problems. Practicing de-contextualized symbolic algebra manipulation routines seldom engages young teenage students and as a captive audience, in a core subject, many who find this thinking difficult become disinterested or even resentful. Both of the above students have made positive comments about using real world contexts for learning mathematics; but there is a difference. The first comment is aligned with a common justification in the literature for exploring real world scenarios; that mathematics becomes more meaningful when students can use their real world knowledge and mathematical knowledge in tandem to reinforce each other. The second comment has no explicit cognitive content and seems purely affective. This student only refers to the way in which the real world context used in the mathematics class brought back (presumably pleasant) memories of childhood. It is unlikely that the mathematical content of the problem, making a profit by selling lemonade, was part of her early experience, so it seems that she is attributing greater interest only to the general link with her past.

In this paper, we report on a series of observations that have led us to examine the second student's response more seriously, and drawn us to the conclusion that concern for positive affect plays a much larger part and a somewhat different role in teaching with real world problems than is recognized in the literature. Previous researchers (see for example Burkhardt, 1981, Mason, 1984, Sowey, 2001) have suggested that students will experience pleasure in finding practical, curious or unexpected solutions to problems. In this paper we report examples where teachers chose contexts not for the intellectual pleasure or practical utility referred to in other analyses, but for the possibilities to increase positive affect through association with pleasant sights, tastes, textures, sound and social experiences.

In this paper we claim that the teachers in our study, consciously or unconsciously, wish to use a 'halo effect' to encourage students to like mathematics in general by associating it with real world contexts that provide pleasurable experiences, often in a simple sensory way. Real world contexts are valued largely because they provide this opportunity.

As we will demonstrate that, although teachers in the present study would aim for such objectives as: fostering general competencies and attitudes; preparing citizens who have critical competence; equipping students with the skills to utilise mathematics for solving problems; giving students a rich and comprehensive picture of mathematics; and prompting mathematics learning of a traditional type (Blum and Niss,1989, p5), their concern to use real world contexts to improve students' liking for mathematics is underestimated in previous literature and not adequately represented in Blum and Niss's composite list, which focuses on motivation from intellectual sources. Teachers' concern also goes beyond the issues dealt with in the body of research 
on students' affect in problem solving, applications and modelling. For example, McLeod (1992), in a major study on affect in mathematical problem solving, is adamant that affective issues play a central role, but the concern centres on how emotional and belief factors impact on students' solving of mathematical problems. The literature published since 1992 also affirms that affective factors and beliefs impact on student learning: in general positive attitudes and beliefs and intrinsic motivation are reflected in increased effort in learning and greater persistence. In the sections below, we analyse ways in which teachers have capitalised on this result by refining tasks to enhance affect from simple pleasures rather than through cognitive factors.

The plan of the paper is as follows. The next part of section 1 describes the sources of data used in developing the thesis of this paper, which has arisen by trying to make sense of a large body of observations and interviews with teachers. The final part of section 1 reports literature on the halo effect mainly from psychology. Sections 2, 3 and 4 are devoted to three parts of our argument. In section 2, we demonstrate the primacy of teachers' concern to improve students' attitudes to mathematics through using real world problems. In section 3, we show how teachers' suggestions for enhancing lessons involving real world problems is dominated by a concern to increase sensory pleasures. In section 4, we present results of a short survey which demonstrates that affective considerations play an important role in teachers' selection of real world contexts. The paper aims to demonstrate that teachers place very high importance on mathematically irrelevant aspects of real world problems; we do not make judgements about whether this is good or bad, since the wider context of the decision making needs to be taken into account.

\subsection{Sources of data}

The comments and quotes which form the evidence presented in this paper are extracted from data collected from school teachers in the RITEMATHS project (HREF1). The project aims to investigate the use of real (R) world context problems with the assistance of Information Technology (IT) to enhance (E) middle secondary school students' engagement and achievement in mathematics. The project works in 6 schools, which represent a diverse cohort of students from government and private schools, girls and co-educational schools and a wide range of socio-economic backgrounds. Several teachers of Years 9 and 10 are involved from each school, attending regular professional development sessions with the project team and trialling lessons in real world contexts, jointly designed by themselves and the researchers. The mathematical focus is on the algebra section of the curriculum which, at this level is mostly concerned with linear and quadratic functions and equations.

The data for this paper was assembled from interviews conducted by researchers with individual teachers in May 2004, February 2005 and 2006; teachers' reflective writing in February 2006; and researchers' notes made at teachers' presentations, when they have reported on tasks they have trialled. The data in the last section of the paper, which validates themes emerging from the extensive interview qualitative data, is from a written survey which presented 2 scenarios to 7 teachers from 5 of the schools at a project meeting in April 2006.

\subsection{The Halo Effect}

The term 'halo effect' dates back to the 1920's work of Edward Thorndike (1920) who, in a study of officers' assessments of their soldiers, found a high correlation between ratings of logically unrelated traits. The ratings of each trait of a soldier were affected by the officer's tendency to think of the soldier as generally good or inferior. "Obviously, a halo of special merit is extended to influence the rating for the special ability, or vice versa" (Thorndike, 1920, p. 27). In the same paper, Thorndike cites a similar phenomenon in ratings of characteristics of teachers and again higher-thanreasonable correlations are evident. For example, ratings of the quality of the teacher's voice and of their interest in community affairs had a correlation of 0.5 ; which is unlikely to be reflected in objective measures. The general conclusion, reported in many instances over the following decades, is that raters' assessments of specific traits of a person or thing are markedly influenced by an overall impression, which may itself be based on little evidence. In marketing, the term 'halo effect' is used to describe the phenomenon of extending a positive view of one attribute or item to an entire brand. For example, there are many internet sites discussing whether the recent success of the iPod has led to the enhancement of the image of all Apple computer products (see for example European Quality, 2006).

Nisbett and Wilson (1977) present experimental evidence that the 'halo effect' does not only cause a global perception to influence impressions of qualities for which the rater has insufficient information. They showed that the general 
impression formed quickly and then it influenced evaluations of attributes even when there was sufficient evidence for a contradictory objective assessment of them. The general impression can override specific data.

The halo effect is one of the oldest and widely known of psychological phenomena and an example of 'cognitive bias'. Theories of the origin of the halo effect generally postulate that human cognition fundamentally seeks consistency (see, for example, Balzer and Sulsky, 1992). In Education, the halo effect has been studied as a threat to the validity of survey data, e.g. for assessing teachers (Nisbett and Wilson, 1977). This is also a major concern in other halo studies in the wider literature. For example, Wirtz and Bateson (1995) measured the effect of fast or slow response time on ratings of consumer satisfaction of otherwise identical on-line banking services. In Education, the halo effect is also related to studies on "educational seduction" which look at how personality characteristics of a teacher might override students' judgements about the quality of the learning that is promoted (e.g. Abrami, Leventhal and Perry, 1982).

This paper takes a different, and we believe novel, look at the halo effect in education. We claim that teachers, largely unconsciously, want to harness the halo effect to improve students' liking of mathematics. By injecting elements of pleasure into the students' experience, they hope that the general impression of mathematics will become more favourable. We claim that, for this reason, pleasure to the senses is a major factor in teacher's choice of real world contexts and in their valuing of certain aspects of lessons. In the sections below, we document the importance that teachers place on improving students' attitudes to mathematics, as well as the ways in which they seek to use real world contexts to inject simple pleasures into students' mathematical experiences.

There is a little discussion of deliberate use of the halo effect in mathematics education. Sowey (2001) explicitly identifies it in his survey of striking demonstrations for teaching statistics.

"A striking demonstration is not just an end in itself; it is also a hook on which to hang an exposition of related, but less immediately appealing, material. The stimulus of the former may then be expected to catalyse study effort on the latter. Exploiting this "halo effect" is an effective way to engender learning that lasts - beyond the semester assessments, beyond the academic year, and, indeed, beyond the end of the degree program. Lasting knowledge should, surely, be a goal of all university education!” (Web section 3 ).

\section{Teachers' Criteria for Selection of Real World Problems}

In this section we detail, from interview data, the criteria which our project teachers typically apply when selecting real world problems to use with their classes. The data is supported by observations of which real world problems teachers have actually selected for use and reuse in their own classes.

We asked the teachers for their views on the features of good real world problems and the value they see in mathematical modelling. A primary focus on constraining problems to the standard curriculum was clear. Thus teachers primarily focused on Blum and Niss's fifth argument (prompting mathematical learning).

Teacher 1: ...enough mathematical content within the problem which satisfies [the state curriculum document].

Teacher 2: We're looking for very easy real life problems, very easy modelling - the numbers are easy - the graph does come out to be a straight line...

Teacher 3: Has to be fairly close to what you are doing. If it is too far away for the students to make the connections themselves then you are in trouble.

Teacher 4: Ones that embody the mathematical concepts that you are trying to teach and perhaps extend the students into a deeper understanding of those concepts.

These interview comments support our observations that real world problems are candidates for selection only if the mathematical solution involves specified mathematics. The students are not being presented with an open problem; in fact in most cases the formulation stage of mathematical modelling is carefully scaffolded so that teachers are confident what mathematics will be used.

Some of the teachers had thought deeply about the mechanisms by which mathematical learning might be improved, as in this comment which is reminiscent of the arguments developed by Realistic Mathematics Education about the transition from 'model of' to 'model for' (Gravemeijer, 1999). 
Teacher 3: I think one of the benefits of real world problem solving is [that it] gives kids one major concrete hook to hang an idea on and the more of those you have, the more you can refer to it when you need to use it somewhere else.

Another theme in teachers' comments about the purpose of real world tasks was to prompt mathematical learning by showing its relevance.

Teacher 4: Well, firstly for relevance, just to see why they're doing the mathematics, but also I guess just to increase the engagement and I think it's just probably a higher order of thinking about problems isn't it.

Teacher 3: Algebra hasn't been used to tie in with reality. I think the possibility of putting photos in there does help kids realise that there are applications for things.

Teacher 7: I hope that what they're going to see is that maths really has a purpose - a whole variety of purposes - because when students are struggling with a concept, they are willing to invest the time if they feel that it is going to be useful to them.

More definitely, though, all the teachers are particularly keen to take opportunities to redress the negative image of mathematics for this age group for whom the study of some mathematics is still compulsory. They were unanimous in expressing a view that their choice of real world problems is greatly influenced by their perception of whether it is likely to lead to increased student interest, engagement and improved attitude toward mathematics. The following goals for real world problem solving were typical:

Teacher 5: Improved mathematical ability and hopefully more of a [pause] not so much a liking, but a less negative attitude is probably all I could hope for. [It will] rarely be a positive attitude towards maths, but I think at least a less negative attitude.

I think probably for the age level we're targeting, it's sport, entertainment, food those sorts of things that we can actually tap into... Those sorts of things they actually use and have some familiarity with.
Teacher 6: I think that it [using real world problems] opens up areas that would be of more interest to them.

In an area that's of interest to the students....something in their community...something that might be of interest to teenagers.

Teacher 2: Our hope is actually once they feel comfortable with the activities (i.e. the real world problems set in class), they will do the maths, for the sake of doing the [abstract] maths itself.

The overall picture to emerge from these interviews is that teachers put first priority on real world problems aligning with the mathematical content which they wish to teach. Problems which do not fit this criterion will not be considered. Then real world problems are selected primarily to improve students' attitudes to mathematics, and then to show its relevance.

In both their choice of real world contexts and presentation of tasks, teachers are aiming for more than short term engagement with the issues at hand. (See Teacher 2's comment above). As we will show in the next section, often features of the tasks that had no bearing on the mathematics were accentuated by the teachers. These were commonly the features which made the task pleasant, exciting or social. These sights, sounds or tastes for example, do not change the nature or level or relevance of the mathematics involved, nor the modelling approach or model which will be developed. We believe teachers are using real world tasks, with carefully selected contexts and suitable enhancement and 'packaging' to generate a positive 'halo effect' for mathematics in general. Rather than using real world problems for the primarily intellectual goals which are set out by Blum \& Niss (1989), teachers at this level want to use them to promote a pleasant, enjoyable picture of mathematics. This theme will be elaborated through examples in the next section.

\section{Enhancing modelling tasks to promote positive affective responses}

In this section we describe four real world problems with emphasis on the enhancements recommended by the teachers. This data comes primarily from presentation sessions when teachers have reported on their work and is supplemented with relevant comments from interviews as listed earlier. The purpose of this section is to highlight how the enhancements that teachers recommended are more often about making the lessons more pleasurable 
than fine tuning the mathematical points of the lesson. This is consistent with their major intention to use real world contexts to improve students' attitudes.

\subsection{Example 1: Barbie Bungee (linear functions)}

Barbie Bungee is very popular with the project teachers. Many variations may be found on the Internet (see, for example, HREF2). One of our teachers playfully suggested this task needs to come marked with a warning for others:

This rapidly becomes a tradition and students apply pressure to have their turn to do this activity.

Barbie is to bungee jump from the upper storey of the school building using a 'rope' made from interlocked 'rubber bands'. The task for students is to establish an algebraic model which they will be able to use to calculate the number of rubber bands which will let Barbie bungee close to the ground but safely survive the big jump. The extended length of the 'rope' of rubber bands is linearly related to their number. During the classroom phase, the height from which Barbie will jump is unknown, so students experiment by dropping the toy on ropes made from different numbers of rubber bands, from ledges at a range of heights (chalk board, window ledge, desk etc). Students measure the length of each drop and number of bands used and find a linear equation linking them. Various approaches can be taken to finding the model depending on students' algebraic, graphical and calculator skills. Students may compare rules and investigate the practical interpretation of the constant (Barbie's height) and the gradient (related to stretch of bands) of their linear models. And then they test their work when their own Barbie jumps.

As a well-constructed modelling problem, this task can be seen to relate to most of Blum \& Niss's (1989) five arguments for using real world problems. It fosters general competencies related to investigation, it contributes to giving students a rich and comprehensive picture of how mathematics is used in society, it develops skills in utilizing mathematics for solving problems and motivates and prompts learning of specific mathematical techniques. It is also what Burkhardt (1981) calls a believable problem. Creating safe bungee jumps for toys is clearly a game, but the idea that someone must use a mathematical model to decide how long to make real bungee jump ropes is quite believable.

Teachers reported that the students worked enthusiastically, making considerable effort to get a good rule because they strongly felt the responsibility for their decisions. Teachers observed that when students were using their own toys they were more likely to deliberately underestimate the number of bands. They erred on the side of safety in order not to damage 'my best Barbie'.

Teacher 7 attributes this heightened emotional involvement to the anxiety of the final test.

"Barbie Bungee. It's the best. ... Students see the results. For too much of the great work we do in mathematics, they don't see the results. With Barbie Bungee, in the end you have walk over and you have to throw the little thing off the balcony and if it smacks into the ground, you have made a mistake and it's there for everyone to see. And they cheer and nobody cares that it's smacked in the ground. Kids remember that they were involved, even years later."

In order to increase the emotional involvement of students who did not own Barbies, teachers encouraged students to bring other toys. The teachers then also found that the range of toys broadened the mathematics of the task. They did recommend against using 'long heavy alligators'!

It is clear that the pedagogical strength of this task derives from its sophisticated design as a modelling task and also from the emotional engagement which it harnesses, and it is the latter which the teachers particularly comment upon. These teenage students enjoyed the opportunity to display and play with their childhood toys. It was a fun social time with links to past pleasant experiences. A 'halo effect' can be created when this response is generalised so that students come to perceive mathematics as a whole in a positive light. It does not mean that students will (only) think that mathematics is about toys and games but that, by association, quite unrelated features of mathematics will be viewed in a more positive way.

\subsection{Example 2: Dirt bike jumps (quadratics)}

BMX stunt bike riding provides a strong context for analysing still and moving images. In this task, students examine video clips of an elite dirt or street bike rider jumping his bike. They then use video analysis software (VidShell, HREF3) to collect data and model the rider's flight through the air. The rider effectively becomes a projectile and so the path of his waist, approximated by a series of points, may be modelled by a quadratic function. Figure 1 
shows marked up data from a short video clip of a BMX rider taking off from a ramp, performing a trick in flight and landing on a second ramp. Students construct the mathematical model of his path to answer questions such as to find where the rider reaches his maximum height, compared with the video. Many associated questions can also be answered using the model, such as from what height must he jump in order to have enough time in the air to perform a certain trick.

As a modelling problem, this task relates to at least three of Blum \& Niss's (1989) arguments for using real world problems. The path of a projectile is an intellectually significant application, which contributes to giving students a rich and comprehensive picture of how mathematics is used in society, even though the students at this level do not appreciate the complexity of the rider not being a point mass. It is also a believable problem. While students know that dirt bike riders in their local parks typically solve these problems by trial and error, it is believable that professional riders and competition track designers might use such mathematics in their planning. Students will get skills to utilize mathematics for practical applications. For prompting mathematics learning, teachers saw value in fitting the quadratics, and finding maximum values graphically and algebraically. In the words of Teacher 3 above, this may provide "one major concrete hook" on which to hang later ideas about optimisation in calculus.

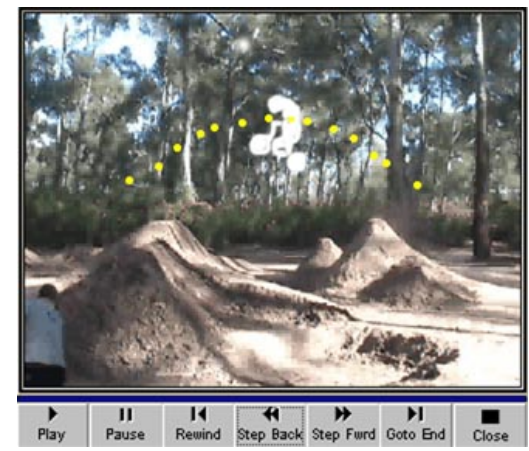

Figure 1 Path of waistline of BMX rider in flight

What have been the teacher's experiences and suggestions for enhancing this task? They pointed to the students' engagement with the task, which they attributed to personal connection, and the excitement of the real world situation.

"Students engaged in the topic more. [...] The activity on its own was of interest to them because they either had a boyfriend a brother who might have been involved in the sport. It is just the exciting nature of the activity I think".
They were keen to point out factors which help present the task in the best way, especially the importance of good sound for creating an exciting atmosphere. It is "best with speakers, to get full atmosphere and create engagement. If possible, don't just use the computer speakers.”

Of secondary interest have been mathematical issues related to the placement of origin of axes for the Cartesian graph and questions of physics have not been discussed. Some teachers instruct all students to place the origin at the same place. Others have commented on how different origin placement affects the quadratic coefficients, but little attention has been given to this interesting mathematical point. Provided the mathematics 'fits' the abstractly specified curriculum, in this case recognising the shape of the parabola and fitting a quadratic, teachers' highest concern is to gain added value by working on those aspects of the task which will create an exciting classroom atmosphere. Then the pleasant memories of the task may, by the 'halo effect' be associated with mathematics generally.

\subsection{Example 3: Biggest box (quadratics)}

Given cards all of the same size, each student makes a box (open-topped rectangular prism) of an individually allocated height by cutting out corners and folding up. They measure the sides of the box, calculate its volume then record height and volume in a table of all class results. This data is then plotted on Cartesian axes and a parabola is fitted through the points, by eye or using a graphics calculator. The students use this formula to find the volume of a box of any dimensions made from the card of the initial size and later generalise to boxes made from card of arbitrary dimensions. The boxes are also used to demonstrate the existence of a maximum volume reached at an intermediate box height. Students initially expected that since they were all starting with same sized sheet of cardboard that their boxes would have same volume.

Using the words of Teacher 3 above, students have found this task to be a "major concrete hook to hang an idea on". This is evidenced by a student who commented to her teacher "ah, this is like the biggest box!” when she was working on another real world task that involved simple optimization.

Teachers recommended enhancements to this problem focused on increasing its visual attractiveness. They reported that students care in making the boxes and their responses to the task were more positive if they were allowed to use coloured paper. Teachers recommended that the 
heights should be allocated in alphabetical order of student name, so that the boxes can be readily collected in order of size from largest to smallest base. Each newly collected box fits inside the previous as they are collected, building a colourful stack (see Figure 2) which prompts reactions of pleasure and surprise from the students. The visual impact of the stack is aesthetically pleasing and demonstrates the preliminary observations that, as the heights increase, the bases of the boxes reduce. However, it does nothing to help students find and solve the mathematical questions involved in this task. If anything, it obscures the 'biggest box'.

The use of colour and building the stack took no extra time but again created a pleasing experience which is likely to generate 'halo effect' to improve students' liking of mathematics. These simple enhancements were valued for the positive responses evoked from the students.

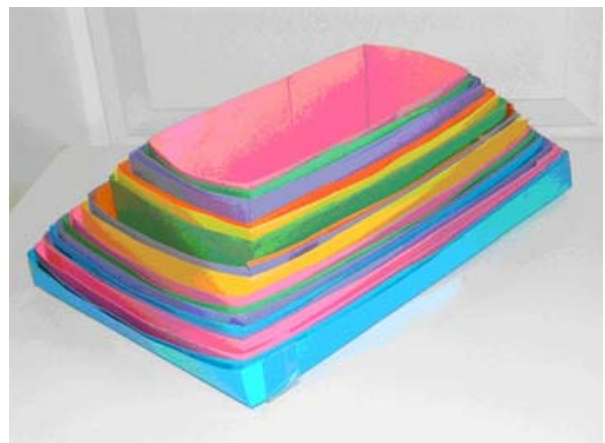

Figure 2: The biggest box is somewhere in the middle of this colourful stack

\subsection{Example 4: McDonald's arches (quadratics)}

For better or worse, McDonald's food, drink, atmosphere and golden arches are very familiar to our students. For this task students use a digital image of the McDonald's golden arches (Figure 3c), plot points around one arch, fit a quadratic curve to these points and then find a mathematical rule for a function which will fit the other curve.

Teachers have enhanced this task by meeting the students at the local McDonald's for breakfast and letting each student use a digital camera to take a photo of the sign. Most students find the breakfast a pleasing mix of taste, smell and social interaction while taking the photo can be exciting, especially standing in the middle of an intersection of a busy road to take the 'best' photo. Later, students were keen to use the (new) digital camera to download the photos to a computer and edit the photo, before beginning the mathematical task. In relation to the time spent, there is very little mathematical thinking involved in this task, and little of significance to be learned from the modelling other than curve fitting.

Teacher 1 explained these choices as follows:

"[It is] very difficult for the individual [teacher] to make it exciting for the kids. What we see as relevant, they may not. .... We tend to say "this is relevant to you" but from the students' point of view, it isn't. So for example, ... they enjoyed that because they ate McDonalds; they enjoyed it because they could come back with the photo and put it through a process. [...] But if you asked them if what they did with the graphics calculator was actually relevant, they would say "no". Relevance to them equates to use in the future and unfortunately the majority of the students that I currently teach do not see in their world that they will be mathematicians or scientists so therefore the relevance of this material to them individually isn't there.”

The quote above highlights that this teacher has no expectation those students will see the mathematics of golden arches as relevant but instead wants it to be enjoyable. This teacher is not inspired by any of the arguments summarised by Blum and Niss (1989) for using real world contexts. Instead of aiming for relevance of the content of real world problem solving to motivate students to learn, he aims for pleasure from the real world link. He hopes that the pleasing experience may colour the students' general view of the mathematics so it is more positive, or at least less negative.

\subsection{Summary}

The four tasks described above all involve the use of real world contexts. Barbie Bungee and the BMX rider task provide real mathematical modelling activities which include an element of prediction and application. The 'biggest box' is more intramathematical but still with a practical application, while the practical application of the golden arches task is superficial. This digital image of the McDonald's arches provides 'eye candy' and motivation for otherwise routine practice of curve fitting. In their reports on the trialling of the tasks, the teachers seem satisfied with the mathematics in the tasks but seek to enhance their affective impact. The features which appeal to the senses and emotions are given attention in order to create a 'halo effect' though which mathematics is associated with enjoyment. Affective overtones are carefully included in the tasks, to make this experience more favourably received, and in turn to make mathematics more favourably received. 


\section{The importance of affect in context choice}

After identifying teachers' concern to enhance factors which promote positive affect as a recurrent theme, the researchers tested the validity of their perception by asking project teachers to respond to two scenarios. The aim of these questions was to see the factors which are most salient when teachers select a task. Teachers were asked to choose from 5 real world contexts for teaching about quadratic graphs (scenario 1) and from 2 contexts for introducing exponential functions (scenario 2). All the teachers are quite familiar with the suggested tasks, having either used them themselves in class, worked through them in professional development sessions, or heard other teachers report their experiences. Scenario 1 examined choices when the differences are within the context only while scenario 2 examined choices where affect was to be weighed against mathematical and management issues. In each scenario, teachers ranked the tasks in the order which they felt would be the most successful in class (using 1 = first choice, $2=$ next choice and so on). They were asked to give reasons for their rankings and, if there was any task which they would not use, then they should explain why.

\subsection{Scenario 1: Quadratic functions}

For the first scenario, teachers were asked to rank 5 different real world contexts to use for teaching about fitting quadratic curves with GridPic (software available from the RITEMATHS website, HREF1). GridPic software can be used to teach students about fitting curves. A photograph is easily imported into GridPic and a grid is placed over it. Cartesian coordinates of points can be obtained automatically. Straight lines, quadratics in different algebraic forms, and other common curves can be plotted in the same window by inputting coefficients in the designated entry-boxes. GridPic can be used with and without the photo, which provides a transition into abstract mathematics. (Pierce, Stacey\& Ball, 2005). Figures 3a and 3c show two photos which teachers in the project had used for teaching quadratics. Figure 3b shows the irrigation spray in Figure 3a with some points marked along the spray and a trial parabola superimposed by the software.

The 5 real world contexts were: the golden arches of your local McDonalds (Figure 3c); water from an irrigation spray (Figure 3a); the water spout of a famous Singapore fountain; the Sydney Harbour bridge; the contours of a car window. The five options focus on the same mathematics but vary in the nature of the context. The irrigation spray and fountain represent situations where there is a physical reason for the shape of the curve and the model could be used for prediction or modified to allow for variation in factors other than gravity. The quadratic in these situations has scientific importance. The Sydney Harbour Bridge and car windows are familiar to students and may be fitted by quadratics to different extents, but this serves no purpose and has other significance. We included the car windows because of the excitement generated in a professional development activity which we ran for teachers. Similarly, fitting a curve to the McDonald's sign serves no purpose but it has a strong association with activities students enjoy. We predicted this would be the most popular with teachers.

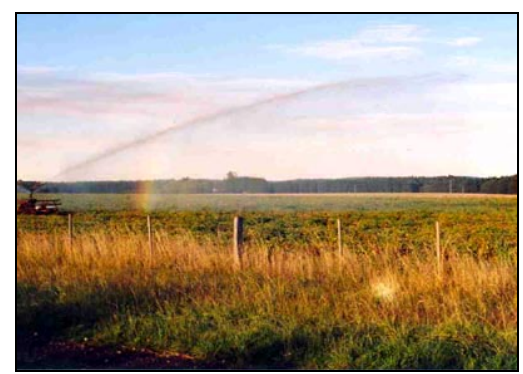

Figure 3a: Irrigation Spray

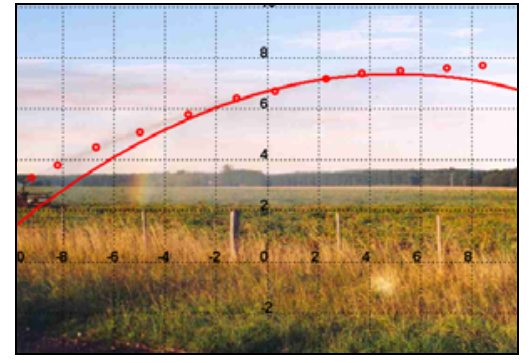

Figure 3b: Irrigation Spray and trial parabola

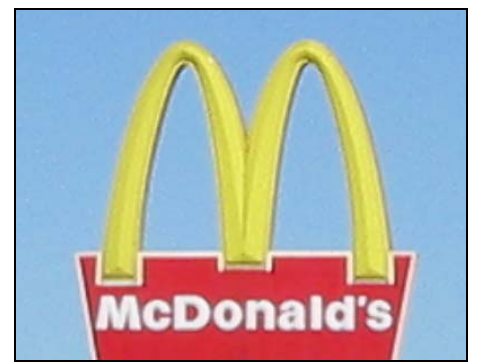

Figure 3c: Golden Arches

Seven teachers responded and their mean rankings (where 1 was the highest rank) were: Golden Arches 2.1; bridge 2.8; irrigation 2.9; fountain 3.3; and window 3.9. As predicted, the context with the highest affective-impact was ranked first, clearly outranking the examples with deeper significance and more options for mathematical modelling. The teachers' reasons have been listed and categorised in 
Table 1. Comments are about students' interest and familiarity dominates, as we predicted.

The frequency of comments on familiarity, and the relative judgements about it, is somewhat surprising, since all of the contexts are everyday things (cars, path of water, bridge). We now believe 'familiarity' is in fact used to reference the complex of "interestfamiliar-like" as is evident behind the quote from Student 2 at the beginning of this paper.

\section{Comments (organised by first choice)}

Interest Familiar Mathematics

Other

\begin{tabular}{|c|c|c|c|c|}
\hline $\begin{array}{l}\text { Golden Arches } \\
\text { Golden Arches is most familiar to students and therefore } \\
\text { would engage them most. Similar reasons for Harbour } \\
\text { Bridge. Others in decreasing order of student interest. }\end{array}$ & $\sqrt{ }$ & $\sqrt{ }$ & & \\
\hline $\begin{array}{l}\text { From the most familiar, to the most accurate, to the less } \\
\text { accurate quadratic functions. }\end{array}$ & & $\sqrt{ }$ & $\sqrt{ }$ & \\
\hline $\begin{array}{l}\text { The photograph has clear edges - excellent plotting } \\
\text { accuracy, with scaling able to be determined. }\end{array}$ & & & & $\sqrt{ }$ \\
\hline $\begin{array}{l}\text { Irrigation Spray } \\
\text { All students would have experienced one or more of } \\
\text { these parabolas and be able to relate to them as "real". } \\
\text { The bridge or car window are more abstract for students. }\end{array}$ & & $\sqrt{ }$ & & \\
\hline $\begin{array}{l}\text { Sydney Harbour Bridge } \\
\text { Most recognisable; a large object which can not be easily } \\
\text { physically measured. }\end{array}$ & & $\sqrt{ }$ & & $\sqrt{ }$ \\
\hline $\begin{array}{l}\text { My students are girls from the city. They have } \\
\text { aspirations to travel. They would be interested in bridges } \\
\text { and fountains ahead of car windows. They would } \\
\text { probably relate more to McDonalds arches than to water } \\
\text { from an irrigation spray. }\end{array}$ & $\sqrt{ }$ & $\sqrt{ }$ & & \\
\hline $\begin{array}{l}\text { Car Windows } \\
\text { Many different designs of car windows so there is scope } \\
\text { for students to test their own. I prefer examples where } \\
\text { the function can be varied which isn't the case with the } \\
\text { McDonalds sign, Bridge or Fountain. McDonalds don't } \\
\text { need any free promotion. }\end{array}$ & & & $\sqrt{ }$ & $\sqrt{ }$ \\
\hline
\end{tabular}

Table 1: Choices and comments on quadratic pictures

\subsection{Scenario 2: Exponential functions}

The second scenario asked for choices between two tasks for an introduction to exponential functions. First, paper folding: repeatedly fold paper in half and tear so that the number of pieces is $1,2,4, \ldots$ Make a table of number of pieces, graph on graphics calculator or computer software, see that $y=2^{x}$ fits. The second task was to scatter a packet of M\&M's (small colourful sweets) onto the table and count the number with symbol upwards. Eat others. Throw remaining M\&M's onto table and count the number with symbol upwards. Eat others. Repeat. Make a table of number of M\&M's at each stage, graph on graphics calculator or computer software, and see that $y=(1 / 2)^{x}$ fits approximately.
These two tasks differ on several dimensions, in particular whether the exponential function fits exactly or approximately and organisational logistics, as well as the attractiveness of the context.

As Table 2 shows, most teachers commented on the mathematical and logistic differences, but they all commented on various aspects of the pleasure associated with the M\&M's ('relate to', 'mundane', 'engagement', 'excitement', interest', 'enjoyable'). However, the teachers were equally divided on which of the two tasks makes the more successful classroom activity, showing the importance that teachers place on positive affect in the classroom, is not to the exclusion of other considerations. 


\begin{tabular}{|c|c|c|c|}
\hline $\begin{array}{l}\text { Paper Tearing } \\
\text { The students would relate more to something edible than to } \\
\text { folding paper [but] I chose to do the paper folding with my } \\
\text { class. I prefer an exact relationship to one where chance is } \\
\text { involved when introducing exponential functions. I have } \\
\text { concerns about a diabetic student in my class when there are } \\
\text { sweets. }\end{array}$ & $\sqrt{ }$ & $\sqrt{ }$ & $\sqrt{ }$ \\
\hline $\begin{array}{l}\text { Paper folding, although more mundane, is a less messy } \\
\text { business than M\&M's on dirty bench tops [...] not to mention } \\
\text { allergies to colour, sweeteners etc. The paper tearing usually } \\
\text { leads to a discussion on the early historical Greek notion of } \\
\text { the atom. }\end{array}$ & $\sqrt{ }$ & $\sqrt{ }$ & $\sqrt{ }$ \\
\hline $\begin{array}{l}\text { M\&M's } \\
\text { [M\&M's] It has a hook for engagement - allows greater } \\
\text { movement - diversity of results and can be simulated as well. }\end{array}$ & $\sqrt{ }$ & & $\sqrt{ }$ \\
\hline $\begin{array}{l}\text { M\&M's generates more excitement in class, is a fun way of } \\
\text { showing an exponential. }\end{array}$ & $\sqrt{ }$ & & \\
\hline $\begin{array}{l}\text { Both } \\
\text { Paper folding is easier to manage in class and would generate } \\
\text { a more accurate model, although M\&M's would generate } \\
\text { more interest. }\end{array}$ & $\sqrt{ }$ & $\sqrt{ }$ & $\sqrt{ }$ \\
\hline $\begin{array}{l}\text { The first [paper folding] is easier to do and has an easier result } \\
\text { to model. The second is far more enjoyable but slightly } \\
\text { harder equation. The first is exponential growth; the second } \\
\text { is exponential decay. Both would be good introductions to } \\
\text { each type. }\end{array}$ & $\sqrt{ }$ & $\sqrt{ }$ & $\sqrt{ }$ \\
\hline Both are equally effective activities. & & & \\
\hline
\end{tabular}

Table 2: Choices and comments on exponential problems

Drawing together the results from both scenarios, we see that affect (in the sense of selecting familiar, interesting, or exciting real world contexts) is a major consideration in teacher choice of real world contexts. Scenario 2 shows that this concern is moderated by logistical concerns (including health concerns) and the pedagogical concerns about the mathematical nature of the real world context (exact vs approximate etc.). However, scenario 1 shows that, for these teachers, concern for positive affect overrides more distant cognitive goals, such as the possibility of using a real world context with intellectual significance (e.g. the physics of projectiles).

\section{Implications and conclusions}

The three sections above have presented evidence for teachers' deep concern with creating a positive (or less negative) liking for mathematics and for the rather surprising way in which they see real world contexts contributing to this. The modelling and applications literature also recognises the importance of using real world problems to motivate students and provide relevance; but this concern arises essentially from intellectual matters. Students, in the arguments in the literature, as summarised for example by Blum and Niss (1989), are seen as being motivated to learn mathematics because of the power it gives them, probably in the future. This power is to be able to use mathematics to solve problems of intellectual interest or affecting their everyday lives or relating to their interests. In contrast, for our teachers, the improved motivation that comes from using real world problems comes from a very direct, here-and-now association with pleasurable things. It is not a power to solve problems of interest, but an association with pleasant things. The explanation of teacher's using simple sensory pleasures and associations to cast a halo over mathematics to improve its image ties together many of our observations.

There are several reasons why there might be a gap between our observations and the literature. Firstly, the teachers in this study are teaching $14-16$ year olds in compulsory mathematics subjects, where 
motivation is a daily concern for teachers. Much of the applications and modelling literature is primarily concerned with older students, who are self-selected to be interested in mathematics. These students, and their teachers, are also more likely to be concerned with intellectual problems of significance. The superficial nature of the quadratic over the McDonald's sign, for example, would be evident to students and teachers who had been working with projectile motion. There is also a difference in the timeframe over which relevance is perceived to operate with the older, more serious students. Our teachers instead look for immediate payoff.

Secondly, as was evident from the interview data, our teachers' primary goal is to teach a set of curriculum topics abstractly defined (e.g. the effect of $a, b$ and $c$ on the graph of the function $f(x)$ $\left.=a x^{2}+b x+c\right)$. Regardless of the intentions of our project team, the teachers do not have a primary intention to teach modelling and problem solving, but instead to teach an unchanged but enhanced curriculum (Blum and Niss's last argument). Very often, researchers begin with a basic intention to encompass a wider range of goals for school mathematics, as is evident in Blum and Niss's first four arguments.

As researchers, we admit to having been somewhat disturbed by uncovering what might be seen as a superficiality in a major part of teachers' reasoning about the use real world problems. We had long been aware, for example, that our software GridPic, could be used to bring what we regard as significant applications into the classroom or simply as 'eye candy'. We now see parallels to the 'eye candy' in many of the teachers' suggestions. However, according to the teachers' reports, the engagement with real world problems throughout the RITEMATHS project, has prompted a positive response in the students, which has been demonstrated in more enthusiasm of mathematics tasks. In turn, this has encouraged the teachers to expand the role of mathematical modelling in their teaching plans.

Real world contexts provide an opportunity for mathematics to benefit from the halo of positive associations. Teachers can use the halo effect as an important part of their pedagogical tool-kit. It is only dangerous if it leads to passing over opportunities to teach substantive mathematics in favour of providing simple sensory pleasures.

\section{Acknowledgements}

The RITEMATHS project (HREF1) is led by Kaye Stacey and Gloria Stillman (University of Melbourne) and Robyn Pierce (University of Ballarat). The researchers thank the Australian Research Council, our six partner schools and Texas Instruments for their financial support of this project and especially the teachers and students who took part in this study.

\section{References}

Abrami, P., Leventhal, L. and Perry, R. (1982). Educational seduction. Review of educational research. 52 (3), 446 - 464.

Balzer, W. K., and Sulsky, L.M. (1992). Halo and performance appraisal research: A critical examination. Journal of Applied Psychology, 77(6), 975 - 985.

Blum, W., and Niss, M. (1989) Mathematical problem solving, modeling, applications, and links to other subjects - State, trends and issues in mathematics instruction. In W. Blum, M. Niss and I. Huntley (Eds) Modelling, applications and applied problem solving. (pp $1-21)$. Chichester: Ellis Horwood.

Burkhardt, H. (1981) The Real World and Mathematics. Glasgow: Blackie.

European Quality (2006). MarketingPlanPro. Retrieved $26^{\text {th }} \quad$ April 2006 from http://www.european-quality.co.uk/Freecontent/Free-articles/The-Brandchannel-annualReaders-Choice-Awards/

Gravemeijer, K. (1999). How emergent models may foster the constitution of formal mathematics. Mathematical Thinking \& Learning, 1(2), 155 177.

HREF1 RITEMATHS Project website. Retrieved $26^{\text {th }}$ April 2006 from: http://extranet.edfac. unimelb.edu.au/DSME/RITEMATHS/

HREF2 Barbie Bungee. NCTM Illuminations. Retrieved $27^{\text {th }}$ April 2006 from http://72.14.203.104/search?q=cache:jRQR4pAm nIgJ:illuminations.nctm.org/Les

HREF3 Vidshell. Web Physics Retrieved $27^{\text {th }}$ April 2006 from

http://webphysics.nhctc.edu/vidshell/vidshell.html

Mason, J. (1984). Modelling: What do we really want students to learn? In J.S. Berry, D.N. Burghes, I.D. Huntley, D.J.G. James and A.O. Moscardini (Eds). Teaching and Applying Mathematical Modelling. pp.215-234 Chichester, England: Ellis Horwood.

McLeod, D. B. (1992). Research on affect in mathematics education: a reconceptualisation. In D. A. Grouws (Ed.), Handbook of research on 
mathematics teaching and learning (pp. 575-596). New York: MacMillan.

Nisbett, R.E. and Wilson, T.D. (1977) The halo effect: evidence for unconscious alteration of judgements. Journal of personality and social psychology. 35 (4), 250 - 256.

Pierce, R., Stacey, K., and Ball, L. (2005) Mathematics from still and moving images. Australian Mathematics Teacher, 61(3), 26 - 31.

Sowey, E.R. (2001). Striking demonstrations in teaching statistics. Journal of Statistics Education Vol 9(1) Retrieved 21-04-06 from http://www.amstat.org/publications/jse/v9n1/sowe y.html

Thorndike, Edward L. (1920) A constant error in psychological ratings. Journal of Applied Psychology. 4, pp 25 - 29.

Wirtz, Jochen and Bateson, John E.G. (1995) An experimental investigation of halo effects in satisfaction measures of service attributes. International Journal of Service Industry Management, 693), 84 - 102.

\section{Authors:}

Pierce, Robyn U., Dr., University of Ballarat, School of Information Technology \& Mathematical Sciences, University Drive, Mount Helen, Victoria, 3350, Australia

Email: r.pierce@ballarat.edu.au

Stacey, K., Prof., University of Melbourne, Faculty of Education - Science and Mathematics Education, Doug McDonell Building, Melbourne, Victoria, 3010, Australia.

Email: k.stacey@unimelb.edu.au 